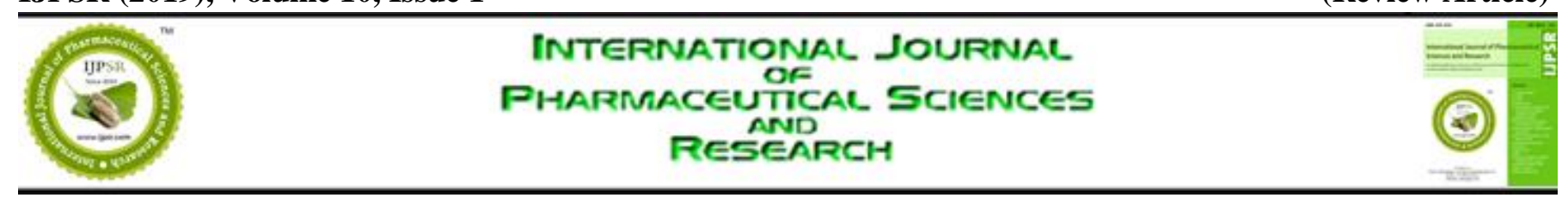

Received on 07 May 2018; received in revised form, 24 July 2018; accepted, 02 August 2018; published 01 January 2019

\title{
A REVIEW ON COLON TARGETED DRUG DELIVERY SYSTEM
}

\author{
Anita $^{*}{ }^{1}$, Anil Singh ${ }^{1}$ and Ankit Dabral ${ }^{2}$
}

Himalayan Garhwal University ${ }^{1}$, Dhaid Gaon, Shiv Nagar, Block Pokhara, Pauri Garhwal - 246169, Uttarakhand, India.

Shri Guru Ram Rai Institute of Technology and Science ${ }^{2}$, Dehradun - 248121, Uttarakhand, India.

Keywords:

Colon drug delivery, Crohn's disease, Inflammatory bowel disease, Lower GI tract, Eudragit S 100

Correspondence to Author:

Anita

Himalayan Garhwal University, Dhaid Gaon, Shiv Nagar, Block Pokhara, Pauri Garhwal -246169, Uttarakhand, India.

E-mail: manju.anita12@gmail.com
ABSTRACT: The oral route is considered to be the most preferred route for administration of drugs for systemic effect, but the oral route is not suitable to the administration of drug for lower gastrointestinal (GI) diseases, this happened due to their release at upper GI tract (stomach, small intestine), which further minimizes the accessibility of drugs at the lower GI tract. To overcome this difficulty, colon-specific drug delivery systems have been broadly analyzed during the last two decades. Colonic drug delivery has gained increased importance not just for the delivery of the drugs for the treatment of local diseases associated with the colon like Crohn's disease, ulcerative colitis, etc. but also for the systemic delivery of proteins, therapeutic peptides, anti-asthmatic drugs, antihypertensive drugs, and anti-diabetic agents. This review article discusses, in brief, the introduction of the colon, factor affecting the colonic transition, colonic diseases and the novel and emerging technologies for colon targeting.
INTRODUCTION: The aim of a targeted drug delivery system is to provide a desired drug concentration in the body by delivering a therapeutic amount of drug to a target site. It is suitable and required for the drugs having instability, low solubility, short half-life, a large volume of distribution, poor absorption, low specificity, and therapeutic index. Targeting may provide maximum therapeutic activity (by preventing degradation or inactivation of drug). Meanwhile, it can also minimize adverse effects, the toxicity of potent drugs by reducing dose ${ }^{1}$. The oral route is the most convenient and important method for administration of drugs for systemic effect.

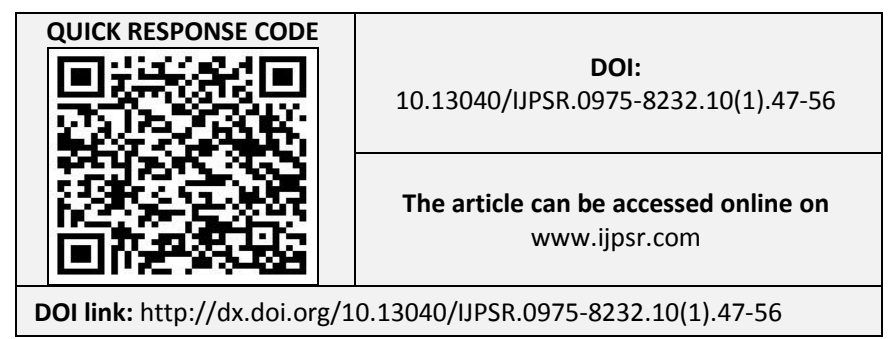

In addition, less pain, reduced risk of crossinfection, needlestick injuries, patient acceptance and ease of administration made it more preferred. Nearly $50 \%$ of the drug delivery systems available in the market are oral drug delivery systems. Apart of these advantages, the oral route is not suitable to the administration of the drug for lower gastrointestinal (GI) diseases; this happened due to their release at upper GI tract (stomach, small intestine), which further minimizes the accessibility of drugs at the lower GI tract.

To overcome this difficulty, colon-specific drug delivery systems have been broadly analyze during the last two decades. By definition, a colonic delivery refers to delivery of drugs accurately into the lower GI tract (by avoiding the drug release in upper GIT), which occurs primarily in the large intestine (i.e. colon) ${ }^{2,3,4}$. Rectal administration is another route used for colon targeting, but it shows less compliance (uncomfortable) and becomes difficult to reach the colon. Conventional dosage 
forms that are used in the prevention of colon diseases (ulcerative colitis, crohn's diseases, amoebiasis) are failing as an improper amount of drug reaches site of action. Conventional dosage form affords the drug to be absorbed from the upper part of GIT, i.e., stomach. This action of conventional dosage form has a serious drawback for colonic localized delivery. Thus, for efficient and safe therapy, the drug is needed to be preserve from upper hostile environment ${ }^{3,5,6}$.

Site-specific delivery into the colon is not only needed for local treatment of a variety of colon diseases, like ulcerative colitis, Chron's diseases, amoebiasis, colon cancer, but also systemic delivery of proteins and peptides this is because of less diversity and intensity of digestive enzymes and less proteolytic activity of colon mucosa than that observed in the small intestine. Beside the colon diseases, this system is also helpful in the treatment of asthma, angina and rheumatoid arthritis for taking advantage of chronotherapeutic drug delivery and for delivery of steroids ${ }^{7}$.

Some factors to be considered for successful colonic drug delivery, including the properties of the drug, the type of delivery system and its interaction with healthy or disease gut. The longer residence time, less peptidase activity, natural absorptive characteristics and high response to absorption enhancers make it most promising site for drug delivery. The absorption enhancers are sub characterized into categories of chelating agents, non-steroidal anti-inflammatory agents, surfactants (mostly as mixed micelles), phenothiazenes and a general class of molecules which include fatty acids, acylcarnitiveacyl amino acids and dicarboxylicacid ${ }^{3,8}$.

\section{Advantages: ${ }^{4,9}$}

- Ideal site for the delivery of active agents to cure the colon diseases (ulcerative colitis, Chron's diseases, amoebiasis, etc.).

- Smaller drug quantities should be required for local treatment.

- Less side effects and drug interactions occurs.

- Dosage frequency is less so, cost effective.

- The long retention time of colon, improved bioavailability of poorly absorbed drug molecules (up to 5 days).
- Reduce gastric irritation caused by many drugs by preventing their absorption in upper GIT (e.g., NSAIDS).

- Bypass initial first pass metabolism.

- Extended daytime or night time activity.

- Limitation and challenges ${ }^{4,9}$

- Hard accessibility of the colon because of its location at the distal part of the alimentary canal.

- The drug may bind non-specifically to intestinal contents (dietary residues, intestinal secretions, fecal matter) cause reduce drugs bioavailability.

- Metabolic degradation of the drug by resident microflora could also affect colonic performance.

- Restrict drug transport across the mucosa and into the systemic circulation due to lower surface area and relative tight junctions in the colon.

- Lack of an appropriate dissolution testing method to evaluate the dosage form in-vitro.

- The drug in solution form required for successful colon delivery or alternatively, it should dissolve in the luminal fluids of the colon, but this can be a limiting factor for poorly soluble drugs.

- Factors to be considered in the design of colonspecific drug delivery system.

- Anatomy and physiology of colon.

The GIT (alimentary canal) is a muscular, digestive tube that extends from mouth to anus, having functions to digest dietary food, to absorb nutrients, electrolytes, and fluids, and to prevent the absorption of potentially harmful substances as shown in Fig. 1.

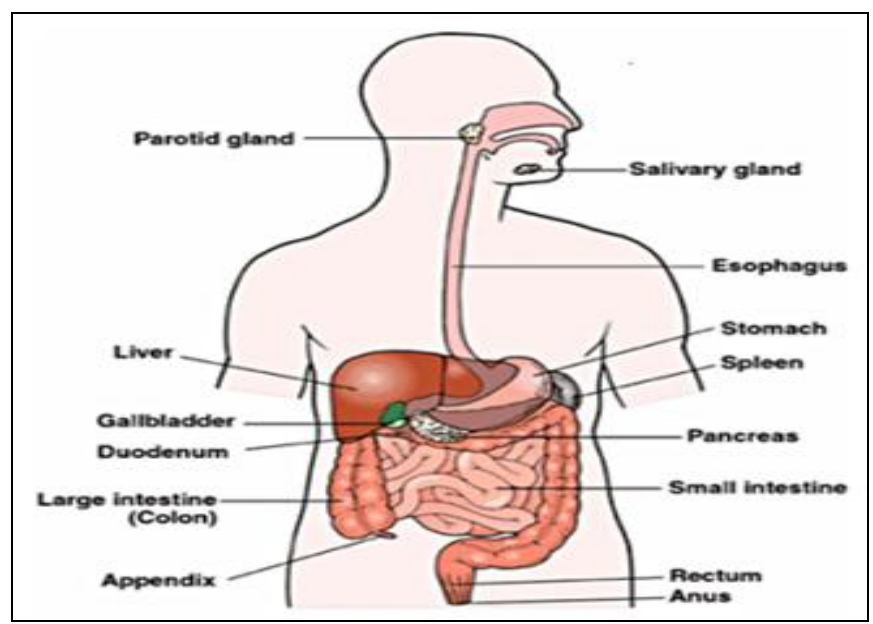

FIG. 1: GASTROINTESTINAL TRACT 
The GI tract is divided into stomach, small intestine, and large intestine. The longest part of the GIT is small intestine where most enzymatic digestion and absorption occur. The large intestine is the last major portion of the GIT (starts from the distal end of the ileum to the anus) and is about 1.5 $\mathrm{m}$ long ${ }^{10}$.

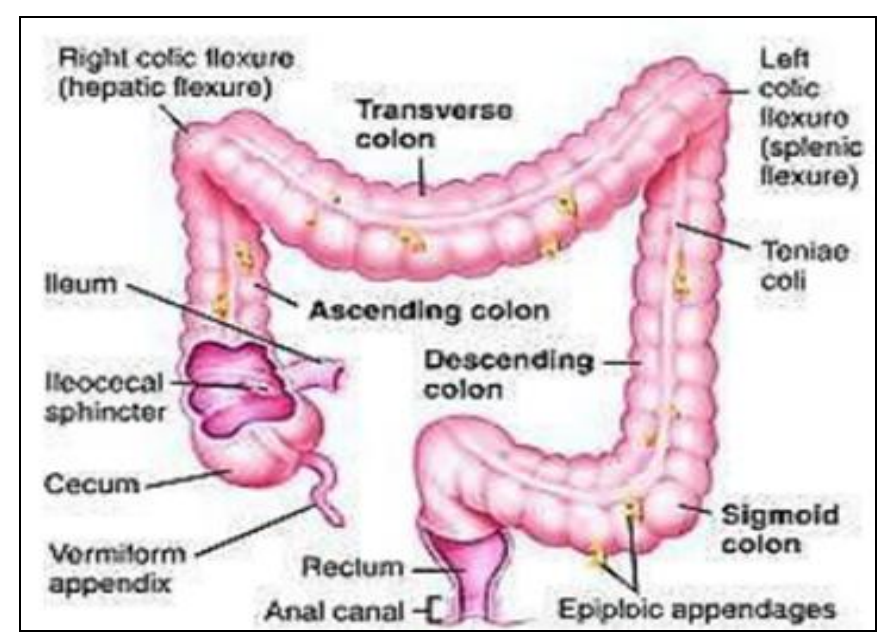

FIG. 2: STRUCTURE OF COLON

Colon is upper five feet of the large intestine and mainly situated in the abdomen. Colon is a cylindrical tube that is lined by a moist, soft pink lining called mucosa as shown in Fig. 2. The cecum is the first part of the colon and leads to the right colon or the ascending colon followed by the transverse colon, the descending colon, sigmoid colon, rectum and the anal canal. The right colon is made up of the cecum, ascending colon, hepatic flexure and the right half of the transverse colon and left colon is made up of the left half of the transverse colon, splenic flexure, descending colon, and sigmoid. The colon does not have villi unlike small intestine, but due to the presence of plicaesemilunares (crescentic folds) the intestinal surface of the colon is increased to approximately $1300 \mathrm{~cm}^{2}$. 9,11

Structure of Colon: ${ }^{1,2,11}$ The colon is made up of different layers and different parts as given in Table 1.

\section{Function of Colon:}

- The consolidation of the intestinal contents into feces by the absorption of the water and electrolytes and storage of feces until excreted from the body.

- To provide a favorable environment for the growth of colonic microorganisms.

- Absorption of $\mathrm{H}_{2} \mathrm{O}$ and $\mathrm{Na}^{+}$from the lumen, and secretion of $\mathrm{K}^{+}$and $\mathrm{HCO}_{3}$.

TABLE 1: DIFFERENT LAYERS AND PARTS OF COLON

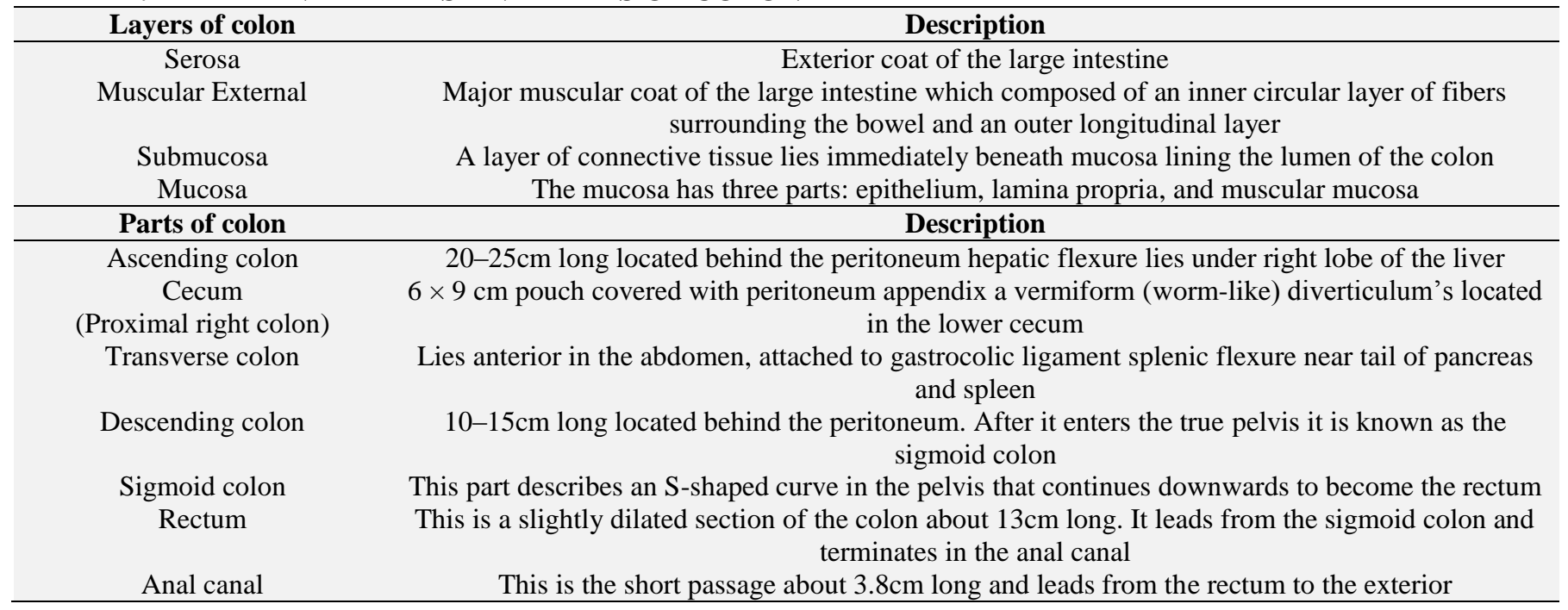

Physiological Factors and Pharmaceutical Factors:

Physiological Factors: ${ }^{6,9,10,11,12}$

Colonic pH: The $\mathrm{pH}$ of the gastrointestinal tract is subject to both inter and intrasubject variations. This $\mathrm{pH}$ variability of the GIT has been used as a means for targeted colon drug delivery and influenced by some factors like diet, diseased state and food intake. Due to the presence of short chain fatty acids (bacterial fermentation of poly saccharides), fall in $\mathrm{pH}$ into the colon has been seen in Table 2. 
TABLE 2: SUMMARY OF ANATOMICAL AND PHYSIOLOGICAL FEATURES OF SMALL INTESTINE AND COLON

\begin{tabular}{|c|c|c|c|c|}
\hline \multicolumn{2}{|c|}{ The region of gastrointestinal tract } & Length (cm) & pH & Internal diameter $(\mathrm{cm})$ \\
\hline \multicolumn{2}{|c|}{ Stomach } & & $1.5-3$ (fasted) & \\
\hline \multirow[t]{3}{*}{ Small intestine } & Duodenum & $20-30$ & $\begin{array}{l}\approx 6.1 \text { (fasted }) \\
\quad \approx 5.4(\text { fed })\end{array}$ & $3-4$ \\
\hline & Jejunum & $150-200$ & $\approx 5.4$ & \\
\hline & Ileum & $200-350$ & $\approx 7-8$ & \\
\hline \multirow[t]{6}{*}{ Large intestine } & Cecum & $6-7$ & $\approx 5.5-7$ & 6 \\
\hline & Transverse colon & 45 & & \\
\hline & Descending colon & 30 & & \\
\hline & Sigmoid colon & 40 & & \\
\hline & Rectum & 12 & & \\
\hline & Anal canal & 3 & & \\
\hline
\end{tabular}

Transit of Material in the Colon: The factors, rate of gastric emptying and the small intestinal transit time influence the delivery of an oral dosage form at the colon as seen in Table 3.

TABLE 3: TRANSIT TIMES OF SMALL ORAL DOSAGE FORMS IN GIT

\begin{tabular}{cc}
\hline Organ & Transit time (h) \\
\hline Stomach & $<1$ (Fasting) \\
& $>3($ Fed) \\
Small intestine & $3-4$ \\
Large intestine & $20-30$ \\
\hline
\end{tabular}

Colonic Micro Flora and their Enzymes: In colon around 400 distinct bacterial species have been found with concentration $10^{11}-10^{12} \mathrm{CFU} / \mathrm{ml}$, of which $20-30 \%$ belongs to genus Bacteroides. Variety of microorganism present throughout the GIT, which further produces enzymes for a metabolic activity like hydrolysis, decarboxylation, dealkylation as shown in Table 4. The bacterial count (Colony forming unit $\mathrm{CFU} / \mathrm{ml}$ ) in different regions of the GIT is $0-10^{3} \mathrm{CFU} / \mathrm{ml}$ in stomach, $0-10^{5} \mathrm{CFU} / \mathrm{ml}$ in jejunum and $10^{3}-10^{7} \mathrm{CFU} / \mathrm{ml}$ in ileum.

TABLE 4: DRUG METABOLIZING ENZYMES IN THE COLON THAT CATALYZE REACTIONS

\begin{tabular}{ccc}
\hline Enzymes & Microorganism & Metabolic reaction Catalyzed \\
\hline Nitroreductase & E. coli, Bacteroides & Reduce aromatic and heterocyclic nitro compounds \\
Azoreductase & Clostridia, Lactobacilli, E. coli & Reductive cleavage of azo compounds \\
Glycosidase & Clostridia, Eubacterium & Cleavage of $\beta$-glycosidase of alcohols and phenols \\
Glucuronidase & E. coli, A. aerogenes & Cleavage of $\beta$-glucuronidases of alcohols and phenols \\
\hline
\end{tabular}

Pharmaceutical Factors:

Drug Candidates:

$\checkmark$ It should poorly absorb from the stomach and small intestine.

$\checkmark$ It should show compatibility with carrier molecule and show stability at alkaline $\mathrm{pH}$ of GIT.

$\checkmark$ It should be used in the treatment of various colon disorders.

Drug Carrier: The carrier selection depends on the physiochemical nature of the drug as well as the disease for which the system is to be used, other factors such as chemical nature, stability and partition coefficient of drug and the type of absorption enhancers chosen.

Colonic Absorption of Drugs: ${ }^{6,11,12}$ Absorption of drugs from colon takes place either transcellular or paracellular route as seen in Fig. 3. Drugs shown to be well absorbed from colon include glibenclamide, diclofenac, theophylline and ibuprofen. Drugs shown to be less absorbed from colon include furosemide, piretanide, buflomedil, atenolol, cimetidine, lithium and ciprofloxacin.

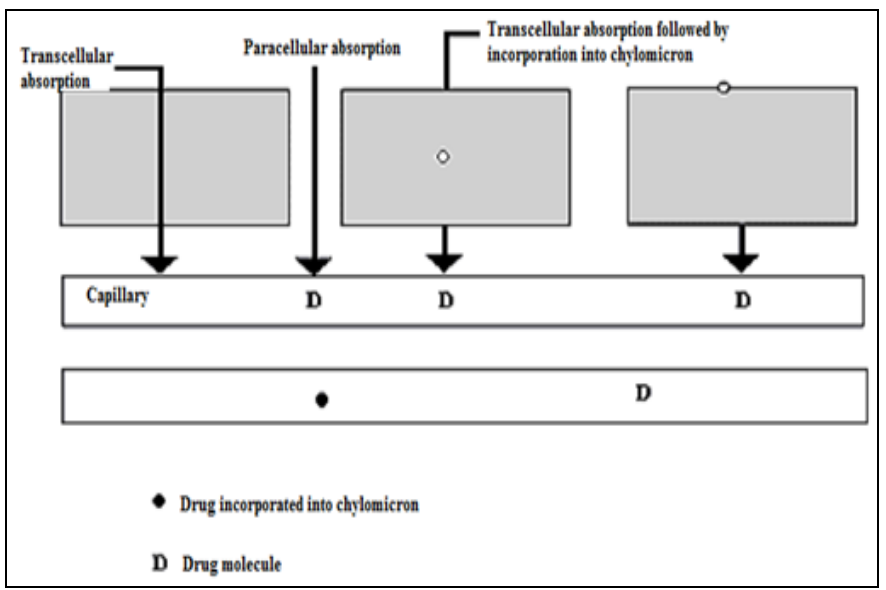

FIG. 3: PRIMARY ROUTES OF DRUGS ABSORPTION FROM THE GASTROINTESTINAL TRACT 
Approaches used for Site-Specific Drug Delivery to Colon (CDDS):

Primary Approaches for CDDS:

\section{pH-Sensitive Polymer Coated Drug Delivery to} the Colon: ${ }^{11,13,14,15,25}$

Principle: Provide coating to the dosage form (e.g., tablets/pellets, etc.) with various $\mathrm{pH}$ sensitive polymers which will produce delayed release formulation and protect it from upper GIT. Most commonly used $\mathrm{pH}$-dependent coating polymers are methacrylic acid copolymers, commonly known as Eudragit S, more specifically Eudragit L and S. These polymers shows insolubility at low $\mathrm{pH}$ levels but become increasingly soluble as $\mathrm{pH}$ rises as shown in Fig. 4.

\begin{tabular}{|c|c|c|}
\hline \multicolumn{2}{|c|}{ Gastro Intestinal tract } & \multirow[t]{2}{*}{$\mathrm{pH}$ dependent system } \\
\hline Anatomical part & $\mathrm{pH}$ & \\
\hline \multirow[t]{2}{*}{ Stomach } & & Intact \\
\hline & & $\mathrm{pH}$ dependent coating \\
\hline Proximal small intestine & 7.5 & DEM \\
\hline \multirow[t]{2}{*}{ Distal small intestine } & 7.5 & In \\
\hline & & $\begin{array}{l}\text { pH dependent coating } \\
\text { start dissolving }\end{array}$ \\
\hline \multirow[t]{2}{*}{ Ceacum } & 6.4 & म, \\
\hline & & Drug release initiated \\
\hline Transverse colon & 6.6 & 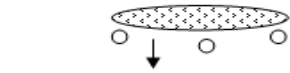 \\
\hline Descending colon & 7.0 & Drug release completed \\
\hline
\end{tabular}

FIG. 4: PRESENTATION OF pH DEPENDENT RELEASE

Thermocoat L 30 D55 is a methacrylic acid copolymer ( $\mathrm{pH}$ dependent polymer) type $\mathrm{C}$ that is an aqueous dispersion of the solid polymer. It is dissolved in the intestine to colon region and used to formulate enteric dosage form for intestinal and colon region ${ }^{26}$.

Some problems associated with this approach are:

- Variability in gastrointestinal $\mathrm{pH}$ between and within individuals and is affected by diet and disease conditions.

- Poor site-specificity (start to dissolve even in the lower small intestine).

\section{Delayed (Time-Controlled Release System) Release Drug Delivery to Colon:}

Principle: Drug release from dosage form should be after a predetermined lag time, i.e., delivers the drug at the right site of action at the right time and in the right amount, Lag time $\approx 5 \mathrm{~h}$ as seen in Fig. 5. Zein was proved to be a potential coating material for a delayed release of drug to colon ${ }^{27}$.
Disadvantages: Variability in gastric emptying time between subjects and depend on type and amount of food intake and gastrointestinal movement.

Example: Enteric-coated time-release press coated tablets

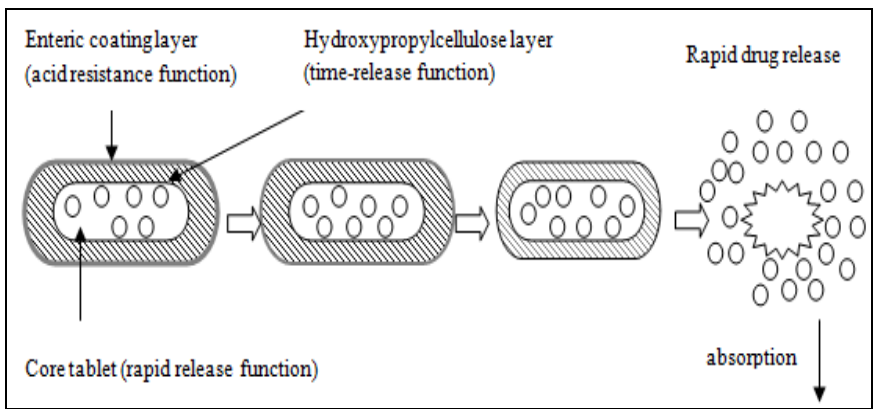

FIG. 5: DESIGN OF ENTERIC COATED TIMEDRELEASE PRESS COATED TABLET

Microbially Triggered Drug Delivery to Colon: Principle: Drug release in colon via degradation of biodegradable polymers coated on the dosage forms by microflora present in colon, because colon is rich in microorganisms. These dosage form protected from upper GIT, due to very little microbial degradable activity in upper GIT is present which is insufficient for cleavage of the polymer coating.

\section{A. Prodrug Approach for Drug Delivery to} Colon: For colonic delivery, the prodrug (a pharmacologically inactive derivative of a parent drug molecule) is designed to undergo minimal hydrolysis in the upper tracts of GIT, and undergo enzymatic hydrolysis in the colon there by releasing the active drug moiety from the drug carrier.

\section{Limitations:}

- Nonversatile approach as its formulation depends upon the functional group available on the drug moiety for chemical linkage.

- Need a lot of evaluation before being used as carriers.

Azo-Polymeric Prodrugs: Sub-synthetic polymers form a polymeric prodrug with azo linkage between the polymer and drug moiety. Azo polymers have been found to be susceptible to cleavage by the azoreductase in the large bowel as shown in Fig. 6. 


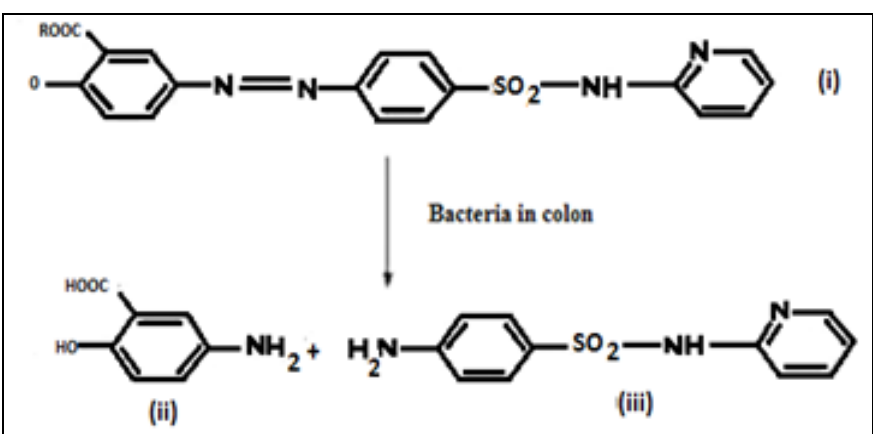

FIG. 6: (I) HYDROLYSIS OF SULPHASALAZINE (II) 5-AMINOSALICYLIC ACID (III) SULFAPYRIDINE.

\section{B. Polysaccharide-Based Delivery System:}

Naturally occurring polysaccharides is used for targeting the colon and found in abundance, inexpensive and are available in a variety of structures with varied properties. They can be easily modified chemically, and are highly stable, safe, non-toxic, hydrophilic and biodegradable. These polysaccharides are obtained from the plant (guar gum, inulin), animal (chitosan, chondroitin sulphate), algal (alginates) or microbial (dextran) origin. The polysaccharides can be broken down by the colonic microflora to simple saccharides. Therefore, they fall into the category of "generally regarded as safe" (GRAS).

Newly Developed Approaches for CDDS: ${ }^{14,}$ 15, 28 Pressure Controlled Drug-Delivery Systems: Contractile activity of the stomach and peristaltic movements for propulsion of intestinal contents required for the digestive process. The pressure generated by muscular contraction of the gut wall is responsible for the grinding and propulsion of the intestinal contents, and changes in the intensity and duration throughout the GI tract, while the colon is considered to have higher luminal pressure due to the process that occurs during stool formation.

\section{Pulsatile Colon Targeted Drug Delivery:}

1) Pulsincap System: These (single-unit) systems are mostly developed in a capsule form. The drug is released as a "Pulse" from the insoluble capsule body by swelling or erosion of plug (control lag time). A swellable hydrogel plug was used to seal the drug contents into the capsule body, and when in contact with the dissolution fluid, it swells, and after a lag time, the plug pushes itself outside the capsule and rapidly releases the drug. The length of the plug and its point of insertion into the capsule controls the lag time.
2) Port System: This system based on the principle of delayed drug release. This system consists of:

- Gelatin capsule coated with a semi-permeable membrane (e.g., cellulose acetate) housing,

- An insoluble plug (e.g., lipidic),

- An osmotically active agent along with the drug formulation.

\section{Novel Colon Targeted Delivery System} (CODESTM): CODESTM is a unique CDDS technology and overcomes problems associated with $\mathrm{pH}$ or time-dependent systems. It is a combined approach of $\mathrm{pH}$-dependent and microbially triggered CDDS. A unique mechanism involving lactulose acts as a trigger for site-specific drug release in the colon as seen in Fig. 7.

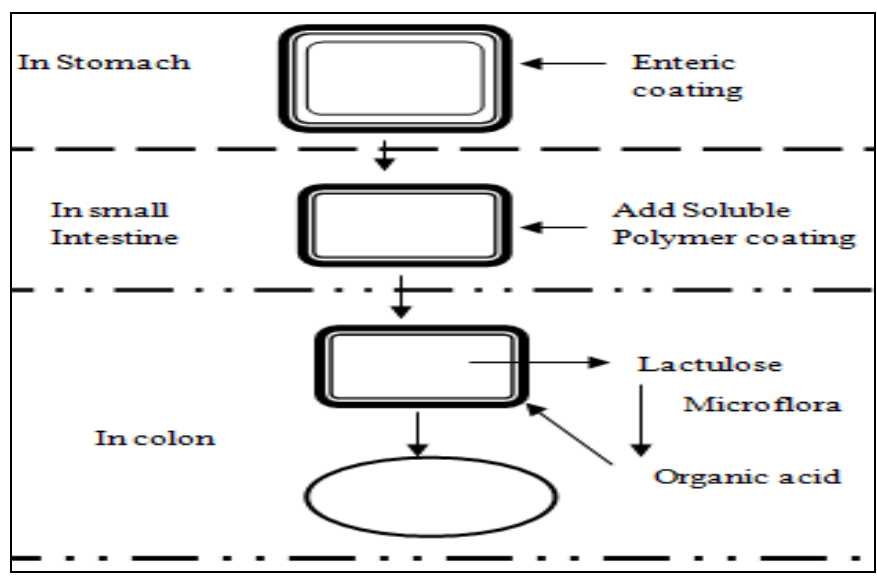

FIG. 7: DESIGN OF CODESTM

Osmotic Controlled Drug Delivery (ORDS-CT): The OROS-CT (Alzacorporation) has been used to target the drug locally to the colon Fig. 8.

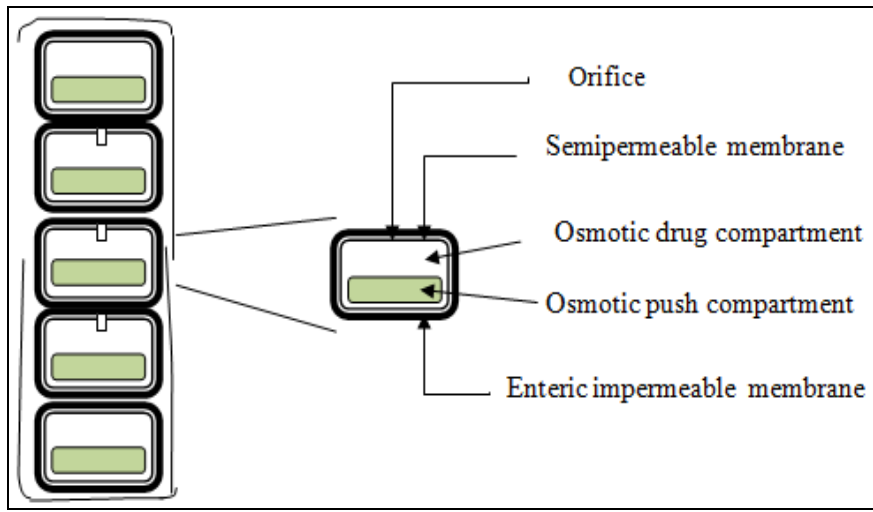

FIG. 8: CROSS-SECTION OF THE OROS-CT SYSTEM

Drug release begins when the unit reached the colon and maintained a constant release rate for up to $24 \mathrm{~h}$ in the colon. 
Multiparticulate System: These formulations consist some minute independent subunits containing active ingredients and are developed by time-controlled explosion system in which drug release is caused by the explosion of a membrane after a definite period which is precisely programmed. It includes formulations such as pellets, granules, microparticles, nanoparticles, and beads. Potential benefits of multiparticulate system:

- Quick delivery, long duration of action, hence increased bioavailability.

- Uniformly dispersed in the GI tract and ensure uniform drug absorption.

- Reduced risk of systemic toxicity, local irritation and predictable gastric emptying.

Pro-biotic Approach: The modern techniques for colon targeting required three components namely probiotic strain (Bifidobacterium and Lacto bacillus), microbial digestible carrier and triggered temperature. These strains triggered to be active at body temperature and the breakdown of carrier take place and lastly release the drug at the desired place. This approach gains success because of the availability of these conditions in colon ${ }^{28}$.

Evaluation of Colon-Specific Delivery: No standardized evaluation technique for CDDS is available because an ideal in-vitro model should possess the in-vivo conditions of GIT such as $\mathrm{pH}$, volume, bacteria, enzymes, enzyme activity and other components of food and these conditions are influenced by the diet and physical stress.

In-vitro Dissolution Test: Conventional basket method may be used for CDDS. Enteric-coated capsules for CDDS have been investigated in three buffers. The capsules were tested for two hours at $\mathrm{pH} 1.2$, then $1 \mathrm{~h}$ at $\mathrm{pH} 6.8$ and finally at $\mathrm{pH} 7.4$.

\section{Dissolution Testing of Polysaccharide-Based} Colon-Specific Drug Delivery: ${ }^{16}$ The most commonly used dissolution testing methods for these delivery systems involve the addition of enzymes, rat caecal contents and human fecal slurries Fig. 9.

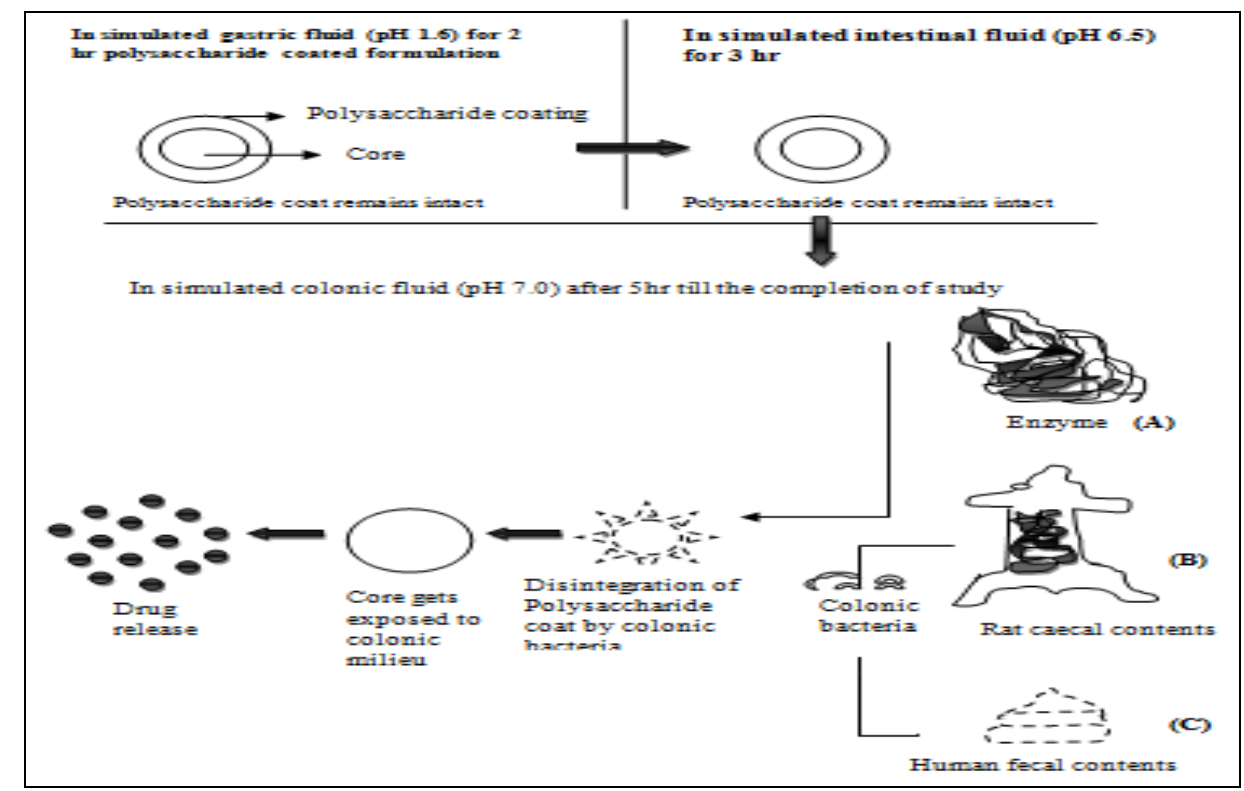

FIG. 9: MECHANISM OF DRUG RELEASE DURING IN-VITRO DISSOLUTION TESTING OF POLYSACCHARIDE BASED COLON TARGETED DRUG DELIVERY SYSTEM USING A. ENZYMES B. RAT CAECAL CONTENTS C. HUMAN FECAL CONTENT

In-vitro Enzymatic Test: ${ }^{28}$ These are 2 tests for the in-vitro enzymatic test.

* Incubation of carrier drug system in a fermenter having a suitable medium for bacteria and determine the amount of drug release at various time intervals.
Incubation of carrier drug system in buffer medium containing enzymes pectinase, dextranase or rat or guinea pig or rabbit caecal contents and determine the amount of drug released in a specific time, i.e., directly proportional to the rate of degradation of the polymer. 
In-vivo Evaluation: ${ }^{28}$ The in-vivo evaluation of the CDDS is done in dog's guinea pigs, rats, and pigs because of the resemblance of anatomic and physiological conditions micro, flora of human GIT, the distribution of various enzymes in GIT of rat and rabbit is comparable to that in human.

\section{Colon Associated Diseases: 17, 18, 19, 20}

\section{TABLE 5: MAJOR DISORDERS OF COLON AND THEIR CHARACTERIZATION}

\begin{tabular}{|c|c|}
\hline Diseases & $\begin{array}{rr}\text { Characterization } \\
\end{array}$ \\
\hline Inflammatory bowel diseases & $\begin{array}{l}\text { Idiopathic chronic multifactorial inflammatory diseases of gastrointestinal tract, which } \\
\text { comprised of two diseases named as ulcerative colitis and crohn's disease }\end{array}$ \\
\hline Ulcerative colitis & $\begin{array}{c}\text { Ulcers form in the inner lining of the intestine, or mucosa, of the colon or rectum, often } \\
\text { resulting in diarrhoea, blood, and pus }\end{array}$ \\
\hline Crohn's disease & $\begin{array}{l}\text { Crohn's disease also called regional enteritis, is a chronic inflammation of the intestines } \\
\text { which is usually confined to the terminal portion of the small intestine, the ileum. }\end{array}$ \\
\hline Colon cancer & $\begin{array}{l}\text { Large bowel cancer includes cancerous growths in the colon, rectum, and appendix. } \\
\text { Colorectal cancers arise from adenomatous polyps in the colon }\end{array}$ \\
\hline Ileus & $\begin{array}{l}\text { It is defined as intestinal obstruction characterized by disruption of the normal propulsive } \\
\text { gastrointestinal motor activity due to non-mechanical causes. Ileus is of three types, i.e., } \\
\text { Postoperative Ileus, Paralytic Ileus, and Acute colonic pseudo-obstruction }\end{array}$ \\
\hline Hemorrhoids & $\begin{array}{l}\text { Hemorrhoids or piles are the varicosities of the hemorrhoidal veins. They commonly result } \\
\text { from increased venous pressure. The possible causes include portal hypertension, chronic } \\
\text { constipation and straining at stool, cardiac failure, venous stasis of pregnancy, hereditary } \\
\text { predisposition, tumors of the rectum }\end{array}$ \\
\hline Irritable bowel syndrome & $\begin{array}{l}\text { Irritable bowel syndrome (IBS) or spastic colon characterized by chronic abdominal pain, } \\
\text { discomfort, bloating, and alteration of bowel habits in the absence of any detectable organic } \\
\text { cause. IBS may begin after an infection or a stressful life event }\end{array}$ \\
\hline $\begin{array}{l}\text { Pseudo } \\
\text { membranous colitis }\end{array}$ & $\begin{array}{l}\text { Pseudomembranous colitis, also known as antibiotic-associated diarrhoea (AAD), is an } \\
\text { infection of the colon often caused by the bacterium clostridium difficile and characterized by } \\
\text { offensive-smelling diarrhoea, fever, and abdominal pain }\end{array}$ \\
\hline Angiodysplasia & $\begin{array}{l}\text { Tortuous dilution of sub-mucosal and mucosal blood vessels in the cecum or right colon, } \\
\text { usually after the age of } 60 \text {. Angiodysplasia is a small vascular malformation of the gut. It is a } \\
\text { common cause of gastrointestinal bleeding and anemia }\end{array}$ \\
\hline
\end{tabular}

\begin{tabular}{ccccc}
\multicolumn{6}{c}{ TABLE 6: } \\
\hline SARKETED DRUG PRODUCTS FOR THE TREATMENT OF VARIOUS DISEASES OF COLON & 21 \\
\hline 1 & Marketed name & Company name & Disease & Drug \\
2 & Mesacol tablet & Sun Pharma, India & Ulcerative colitis & Mesalamine \\
3 & Asacol & Winmedicare, India & Ulcerative colitis, Crohn's disease & Mesalamine \\
4 & SAZO & Wallace, India & Ulcerative colitis, Crohn'sdisease & Sulphasalazine \\
5 & Intazide & Intas, India & Ulcerative colitis & Balsalazide \\
6 & COLOSPA & Solvay, India & Irritable colon syndrome & Mebeverine \\
\hline
\end{tabular}

\section{Colon Specific Polymers: ${ }^{14,22,23}$}

Guar Gum: Guar gum obtained from the seeds of Cyamposis tetragonoloba and composed of the sugars galactose and mannose. The backbone is a linear chain of $\beta$-1,4-linked mannose residues to which galactose residues are 1,6-linked at every sec mannose, forming short side-branches Fig. 10. Guar gum is used in colon targeted drug delivery systems due to its drug release retarding property and susceptibility to microbial degradation in large intestine.

Xanthan Gum: Xanthan gum is high molecular weight extracellular polysaccharide produced by the fermentation of the gram-negative bacterium Xanthomonas campestris Fig. 12. Xanthan is a free-flowing powder, give viscous solutions at low concentrations and offer very good stability. Xanthan gum and hydroxypropyl methylcellulose were used as hydrophilic matrix agents for preparing modified release tablets of diltiazem $\mathrm{HCl}$.

Alginates: Alginates are linear polymers that have 1-4'linked $\beta$-D-mannuronic acid and $\alpha$-L-guluronic acid residue arranged as blocks of either type of unit or as a random distribution of each type Fig. 11. 


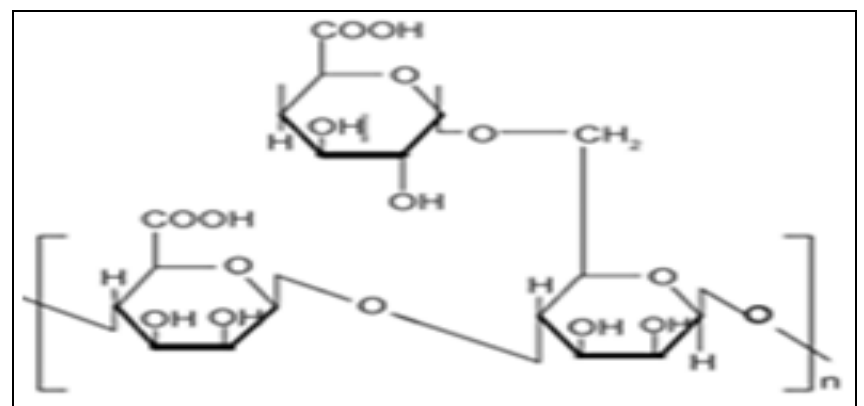

FIG. 10: CHEMICAL STRUCTURE OF GUAR GUM

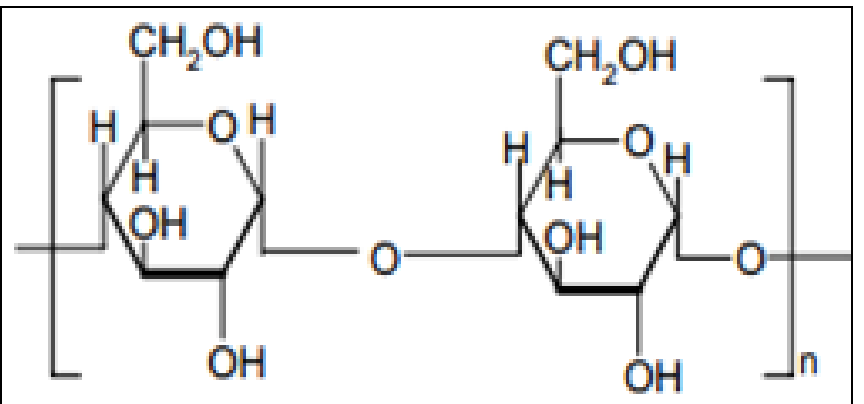

FIG. 11: CHEMICAL STRUCTURE OF SODIUM ALGINATE

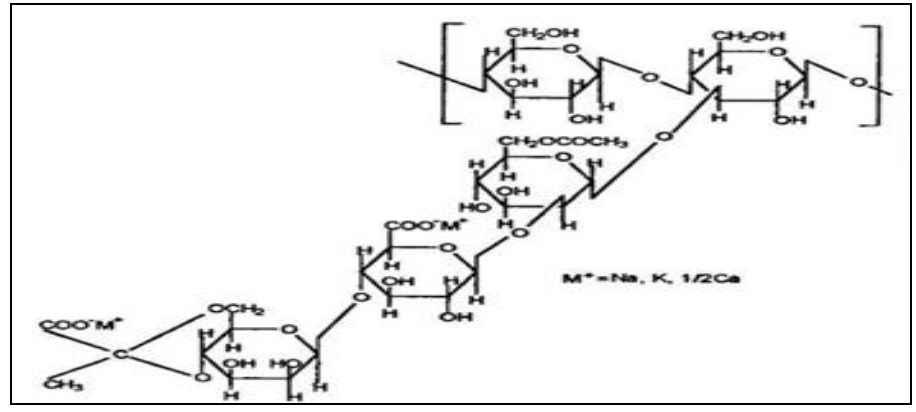

FIG. 12: CHEMICAL STRUCTURE OF XANTHAN GUM

Synthetic Polymers in Colon Targeting: 22, 24 Synthetic polymers should be able to withstand the lower $\mathrm{pH}$ values of the upper GIT (stomach, small intestine) and also be able to disintegrate at the neutral of slightly alkaline $\mathrm{pH}$ of the terminal ileum. Mostly used $\mathrm{pH}$-dependent polymers are derivatives of acrylic acid and cellulose (Like Eudragit L 100-6.0, Eudragit S 100-7.0, Cellulose acetate phthalate.)

Cellulose Acetate Phthalate: Cellulose acetate phthalate was synthesized in 1940 by Hiatt and was one of the first polymers used for its enteric properties. The CAP polymer exhibits rapid dissolution at a $\mathrm{pH}>6$. The addition of a plasticizing agent (Diethyl phthalate triacetin) has been shown to improve the water resistance of CAP films. It is practically insoluble in water and ethanol; soluble in acetone. CAP concentrations in oral formulations are typically limited to $0.5-0.9 \%$ of the tablet core weight.

CONCLUSION: Colon targeted drug delivery system generate both local and systemic effects. The main advantage of colon drug delivery system is, long transit time, near neutral $\mathrm{pH}$, reduced enzymatic activity and increased responsiveness to absorption enhancers. The main aim of CDDS is to preserve the formulation during its transit through the stomach and small intestine. There are some novel approaches more specific compared to primary approaches like pressure controlled drug delivery system, pulsincap system, port system; colon-targeted delivery system (CODES), multiparticulate system and pro-biotic. Both polysaccharides and synthetic polymers are used for the colon targeting. The colon targeted drug delivery provides safe, effective and less expensive delivery of drugs with minimum fluctuation at the target site.

\section{ACKNOWLEDGEMENT: Nil}

\section{CONFLICT OF INTEREST: Nil}

\section{REFERENCES:}

1. Kannadasan M, Kumar RR and Kumar VS: Pharmaceutical approaches to colon targeted drug delivery systems. Research Journal of Pharmaceutical, Biological, and Chemical Sciences 2014; 5(5): 1811-1822.

2. Bhalersao SD and Mahaparale PR: Different approaches to colon drug delivery systems. International Journal of Research and Reviews in Applied Sciences 2012; 2(3): 529-549.

3. Asija R, Chaudhari B and Aseeja S: Oral colon targeted drug delivery system: current and novel perspectives. Journal of Pharmaceutical and Scientific Innovation 2012; 1(5): 6-12.

4. Mehta TJ, Patel AD, Patel MR and Patel NM: Need for colon-specific drug delivery system: primary and novel approaches. International Journal of Pharmaceutical Research and Development 2011; 3(1): 134-15.

5. Jawalkoti SP, Jadhav PD, Mane SV and Khade MM: Colon targeted drug delivery system. International Journal of Pharmaceutical Research and Bioscience 2013; 2(2): 122-136.

6. Patel A, Bhatt N, Patel KR, Patel NM and Patel MR: Colon targeted drug delivery system. Journal of Pharmaceutical and Biosciences 2011; 1(1): 37-49. 
7. Qureshi AM, Momin M, Rathod S, Dev A and Kute C: Colon targeted drug delivery system: current approaches. Indian Journal of Pharmaceutical and Biological Research 2013; 1(4): 130-147.

8. Gopinath H, Kapudasi RK, Shanmuga D, Bhowmik D, Bada PK, Venugopal KS and Shanmugasundaram S: Review on, colon-specific drug delivery Strategies and invitro in-vivo evaluation. Elixir Pharmacy 2013; 57: 1395513963.

9. Balvir S, Patel MR, Patel KR and Patel NM: A review on colon targeted drug delivery system. International Journal of Pharma and Bio Sciences 2013; 2(1): 20-34.

10. Shetty A, Prabhu S, Parsekar S, azharuddin $M$ and Shabaraya AR: Colon targeted drug delivery systems: a novel approach to drug delivery. The International Journal of Pharmaceutical Res and Bioscience 2014; 3(2): 49-67.

11. Vemula SK and Veerareddy PR: Different approaches to design and evaluation of colon-specific drug delivery systems. International Jour Pharm Tech 2009; 1(1): 1-35.

12. Challa T, Vynala V and Allam KV: Colon-specific drug delivery systems: primary and novel approaches. International Journal of Pharmaceutical Sciences Review and Research 2011; 7(2): 171-181.

13. Wasnik S and Parmar P: The design of colon-specific drug delivery system and different approaches to treat colon disease. International Journal of Pharmaceutical Sciences Review and Research 2011; 6(2): 167-177.

14. Satpute CS, Pagare PK, Jadhav VM and Kadam VJ: Potential approaches of colon targeted drug delivery system. American Journal of Pharma Tech Research 2012; 2(4): 311-328.

15. Philip AK and Philip B: Colon targeted drug delivery systems: Primary and novel approaches. Oman Medical J 2010; 25(2): 79-87.

16. Kotla NG, Gulati M, Singh SK and Shivapooja A: Facts, fallacies, and future of dissolution testing of polysaccharide-based colon-specific drug delivery. J Controlled Release 2014; 178: 55-62.
17. Nidhi, Rashid M, Kaur V, Hallan SS, Sharma S and Mishra N: Microparticles as controlled drug delivery carrier for the treatment of ulcerative colitis. Saudi Pharmaceutical Journal. 2016; 24(4): 458-472.

18. Gangurde HH, Chordiya MA, Tamizharasi $\mathrm{S}$ and Sivakumar T: Diseases, approaches and evaluation parameters for colon-specific drug delivery. International Journal of Drug Research and Technology 2012; 2(3): 239-262.

19. Nasrallah A and El- Sibai M: Colorectal cancer causes and treatments. The Open Colorectal Cancer Jour 2014; 7: 1-4.

20. Gupta A, Mittal A and Gupta AK: Colon targeted drug delivery systems -a review 2011; 3(4): 3-13

21. Singh N and Khanna RC: Colon targeted drug delivery systems- A potential approach. The Pharma Innovation 2012; 1(1): 38-45.

22. Neha S and Harikumar SL: Polymers for colon targeted drug delivery. International Journal of Drug Development and Research 2013; 5(1): 21-31.

23. Kulkarni VS, Butte KD and Rathod SS: Natural PolymersA comprehensive review. International Jour of Research in Pharmacy and Biomedical Sci 2012; 3(4): 1597-1613.

24. Rathore VS, Tanwar YS, Rathore GS and Ahmed JA: A Review on enteric coating technology. International Journal of Chemical and Pharmaceutical Sciences 2014; 2(9): 1155-1159.

25. Sharma MK and Mishra N: Review article on various approaches used for colonic drug delivery system. Asian Journal of Biomaterial Research 2017; 3(2): 18-39.

26. Jain A: Colon targeting using $\mathrm{pH}$-sensitive materials advance research gastroenterology and Hepatology 2018; 8(5): 1-3.

27. Nguyen MNU: Development of a Zein-Based System for Colon-Specific Delivery 2018; 505-508. https://doi.org/10. 1007/978-981-10-4361-1_85

28. Saxena S, Singh C, Yadav M and Samson AL: A review on novel approaches for colon targeted drug delivery systems; PharmaTutor 2018; 6(7): 11-22.

How to cite this article:

Anita, Singh A and Dabral A: A review on colon targeted drug delivery system. Int J Pharm Sci \& Res 2019; 10(1): 47-56. doi: 10.13040/ IJPSR.0975-8232.10(1).47-56.

All @ 2013 are reserved by International Journal of Pharmaceutical Sciences and Research. This Journal licensed under a Creative Commons Attribution-NonCommercial-ShareAlike 3.0 Unported License.

This article can be downloaded to ANDROID OS based mobile. Scan QR Code using Code/Bar Scanner from your mobile. (Scanners are available on Google Play store) 